\title{
La influencia de la orientación de meta en la satisfacción, la implicación académica y el logro delalumno
}

\author{
Heinke Roebken
}

Departamento de Educación, Universidad de Oldenburg

\section{Alemania}

Heinke Roebken. University of Oldenburg, Department of Education. Uhlhornsweg 49. 26129 Oldenburg. Alemania. E-mail: h.roebken@uni-oldenburg.de

(C) Education \& Psychology $\mathrm{I}+\mathrm{D}+\mathrm{i}$ and Editorial EOS (Spain) 


\section{Resumen}

Introducción. Varios estudios han mostrado que la clase de orientación de meta determina las reacciones cognitivas y de comportamiento de los estudiantes así como su rendimiento académico (e.g. Ames 1992, Ames/Archer 1988, Valle et al. 2003). Contrario a muchos puntos de vista, este estudio percibe la orientación de meta como un constructo multidimensional con distintos componentes y pone a prueba la manera de la que los objetivos múltiples están relacionados con el comportamiento y resultados académicos del alumno. Además, este trabajo examina cómo las múltiples metas de logro están relacionados con distintas características socio-demográficas. Finalmente, se evalúa la influencia relativa de la orientación de meta en los índices de satisfacción, logro e implicación académica en los estudiantes de carrera.

Método. Este trabajo usa datos de 2309 estudiantes universitarios de la University of California Undergraduate Experience Survey (UCUES). UCUES proporciona datos longitudinales acerca de la implicación académica de los estudiantes, implicación cívica, tecnología instruccional, y políticas y prácticas académicas de la institución. Usando análisis de conglomerados (cluster), se establecen distintos grupos de estudiantes basados en su orientación de meta, hacia el dominio, rendimiento o evitación del trabajo. A través del análisis de la varianza, el autor analiza cómo las distintas orientaciones de meta están relacionadas con la satisfacción, logros académicos e implicación académica del alumno.

Resultados. Los resultados apoyan la noción de que los estudiantes que persiguen metas de dominio así como de rendimiento están más satisfechos con su experiencia académica, muestran un mayor grado de implicación académica y obtienen mejores calificaciones que aquellos estudiantes que tienen únicamente una orientación de meta de dominio o una orientación de evitación del trabajo/rendimiento.

Conclusión. Los hallazgos tienen implicaciones tanto teóricas como prácticas. Con respecto al debate sobre la teoría de metas, los hallazgos actuales apoyan la perspectiva de múltiples metas, sugeriendo que las metas tanto de dominio como de rendimiento pueden facilitar el logro y la satisfacción. Una implicación práctica del estudio de la orientación de meta es que los candidatos para acceso a la universidad pueden ser filtrados a base de a una alta orientación hacia el dominio así como hacia el rendimiento. 
Palabras clave: orientación de meta, actitudes del alumno, teoría de metas múltiples, logro, satisfacción, implicación académica

Recepción: 27-03-07 Aceptación Provisional: 02-11-07 Aceptación definitiva: 23-11-07 